\title{
Let's Take it to the Clouds: The Potential of Educational Innovations, Including Blended Learning, for Capacity Building in Developing Countries
}

\author{
Hannah Marrinan $^{1 *}$, Sonja Firth ${ }^{1}$, David Hipgrave ${ }^{2}$, Eliana Jimenez-Soto ${ }^{1}$
}

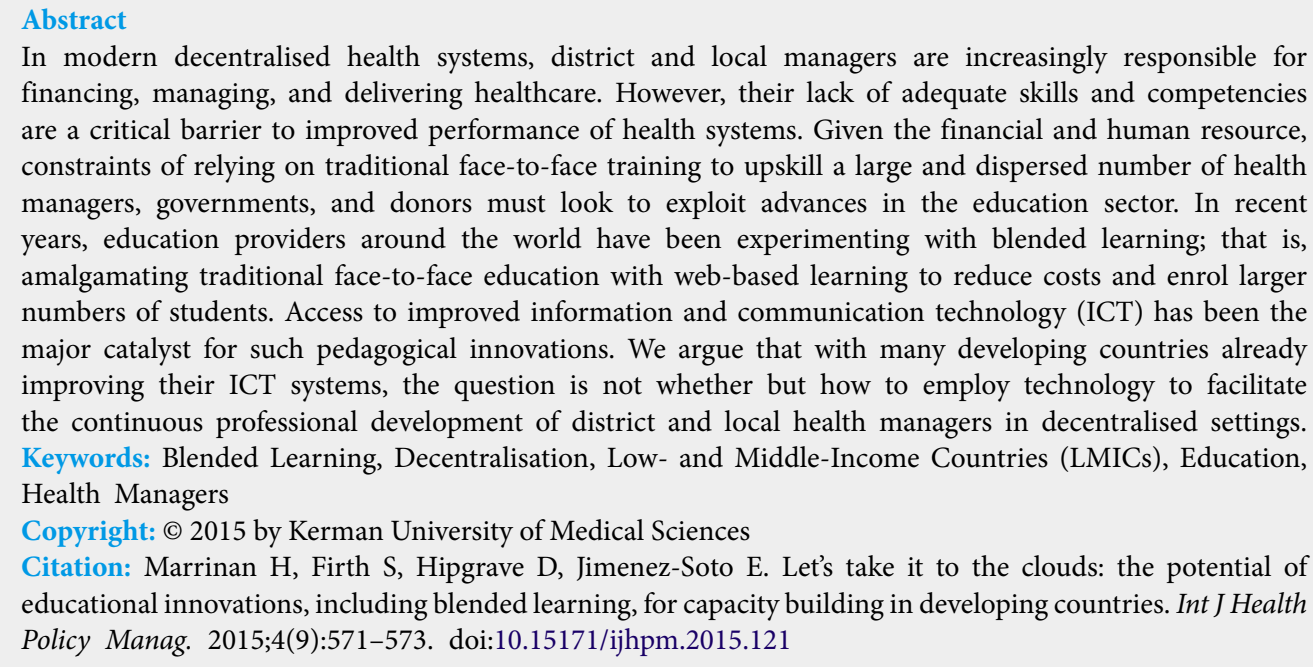

In modern decentralised health systems, district and local managers are increasingly responsible for financing, managing, and delivering healthcare. However, their lack of adequate skills and competencies are a critical barrier to improved performance of health systems. Given the financial and human resource, constraints of relying on traditional face-to-face training to upskill a large and dispersed number of health managers, governments, and donors must look to exploit advances in the education sector. In recent years, education providers around the world have been experimenting with blended learning; that is, amalgamating traditional face-to-face education with web-based learning to reduce costs and enrol larger numbers of students. Access to improved information and communication technology (ICT) has been the major catalyst for such pedagogical innovations. We argue that with many developing countries already improving their ICT systems, the question is not whether but how to employ technology to facilitate the continuous professional development of district and local health managers in decentralised settings. Keywords: Blended Learning, Decentralisation, Low- and Middle-Income Countries (LMICs), Education, Health Managers

Copyright: @ 2015 by Kerman University of Medical Sciences

Citation: Marrinan H, Firth S, Hipgrave D, Jimenez-Soto E. Let's take it to the clouds: the potential of educational innovations, including blended learning, for capacity building in developing countries. Int J Health Policy Manag. 2015;4(9):571-573. doi:10.15171/ijhpm.2015.121

\section{Article History:}

Received: 10 May 2015 Accepted: 25 June 2015 ePublished: 27 June 2015

\footnotetext{
*Correspondence to: Hannah Marrinan Email: hannah.marrinan@gmail.com
}

\section{Introduction}

A large number of low- and middle-income countries (LMICs) have decentralised their health system, ${ }^{1,2}$ making district and local leaders responsible for planning, budgeting, and managing health services. Decentralisation is intended to reduce current patterns of inequity ${ }^{3-5}$ and improve service delivery by encouraging the development of local solutions and accountability for local problems. ${ }^{6}$ However, at lower levels of the health hierarchy, many health managers lack the skills and competencies needed to run a health system, particularly those located in the most remote or poor locations. ${ }^{2}$ Moreover, better qualified personnel often refuse to work in such locations, and those interested in building their skills are the most likely to seek employment or training opportunities elsewhere. ${ }^{7}$

Continued professional development for rural health workers is therefore essential to improve health systems in LMICs, especially decentralised nations with insufficient and/ or poorly qualified personnel. ${ }^{8}$ However, traditional faceto-face training can be prohibitively expensive and places significant emphasis on human and financial resources which are often unavailable in large or resource-constrained settings. ${ }^{8}$ In Indonesia, for example, a bottom-up approach to planning and budgeting health services would require a large scale capacity building program targeting 33 provinces, 497 districts/municipalities and 6651 subdistricts. Taking such planning and budgeting closer to the community would entail building the capacity of government officials in 77126 villages. Alternatives to face-to-face training, particularly in rural and remote communities must be sought in order to train workforces constrained by financial burden as well as physical barriers. ${ }^{9}$

With the pressure to reduce costs, increase access and improve the efficiency and technical content of training, technology is now being utilised to provide learning solutions. While the concept of online learning is not new, as technologies become more sophisticated, so do the modalities employed. The introduction of new information and communication technology (ICT) over recent decades has paved the way for online learning platforms to grow and diversify with the needs of users.

Several platforms make use of ICT infrastructure, including standard online courses, massive open online courses (MOOCs) and blended learning. The use of such e-learning tools has resulted in the motto "anytime, anywhere, anybody" in relation to online education in high-income countries. ${ }^{10}$ They offer individuals the opportunity to engage in webbased courses which remove geographical barriers to learning whilst also reducing costs. ${ }^{11}$ Well-designed online courses with solid instruction design and that are part of an academic curriculum can be equivalent to standard face-to-face instruction. ${ }^{12}$ However, e-learning courses not offering clear 
academic incentives (like many MOOCs) face high attrition rates. ${ }^{9,11}$

The education sector embarked upon the 'blended learning' approach to teaching, which amalgamates face-to-face instruction with web-based learning for better engagement of students. ${ }^{13}$ Such blended approaches can substantially reduce the cost of training and education, ${ }^{14}$ while also providing faceto-face learning components to appease the need for feedback and engagement. Blended learning has been identified as a platform which can provide 'real world, plus in-world' solutions to education. ${ }^{15}$ Indeed, a recent meta-analysis found that students receiving blended learning instruction performed better on average than those receiving face-toface instruction, though this was not attributed entirely to the mode of delivery. ${ }^{12}$ Universities are a prime example of institutions which effectively impart blended learning, as most offer an 'on-site' location for students to attend classes while also supporting a virtual classroom where students access online learning materials. These materials can be stored online beyond the duration of a course, reducing administrative effort, while allowing current students the 'anytime and anywhere' flexibility of e-learning. This has the potential to support the learning outcomes of students, as study can be considered to be self-directed while being facilitated by teaching staff and mentors.

Adapting teaching platforms which combine online technologies and cloud computing in the health sector can provide opportunities for managers to create local solutions to local problems through tailored capacity building at a more reasonable cost. Blended learning retains some of the lower cost of computer-based training but circumvents some of the identified constraints; in particular it provides context for local problems in the face-to-face or more personalised component of a course. ${ }^{9}$ As with students in higher education, health staff who participate in this type of learning for continued professional development are able to control their own learning outcomes whilst also engaging with mentors who can augment the learning process through direct support and supervision. ${ }^{16}$ Instructors are also better able to exploit the relative advantages of both the e-learning and face-to-face components. However, in order to be truly successful, blended learning requires strong coordination of both components, including which aspects of the course are best suited to each learning environment. This coordination can incur high transaction costs for providers.

A review of training programs for health workers in LMIC examined the potential and challenges of blended learning. ${ }^{8}$ It noted that distance learning programs have the ability to meet the education and training needs of health workers in LMIC. Moreover, the infrastructure constraints noted in the early initiatives, particularly in Africa, have decreased in recent years. The number of internet users in Africa is growing at a rate 7 times the global average ${ }^{17}$ and low cost tablets and computers are making hardware more easily available in LMIC. ${ }^{10}$ However, the base from which these advances are made is very low in least developed countries where only $7 \%$ of households have internet access. ${ }^{18}$ In this case, without major infrastructure developments, innovative education technologies will be of limited use. On the other hand, in developing countries where on average $34 \%$ of households have internet access, ${ }^{18}$ governments and donors should take advantage of growing technology penetration to allow health personnel to benefit from blended learning approaches. Technological issues however are only one side of the equation; other critical factors required to unlock the potential of this approach include $(a)$ an environment that facilitates timely support and opportunities for interactions to examine material in-depth and clarify questions (ie, trained mentors or experts; political and financial support; adequate time off $)^{19}$; (b) appropriate system components (appropriate hardware and bandwidth) that ensure not only robust ICT infrastructure, but user-friendly interfaces, along with flexible and pedagogically well-designed material ${ }^{20}$; and (c) personal factors including the motivation, characteristics and technical capacity of learners and instructors..$^{21,22}$

Blended approaches have been introduced in other areas of the private sector and government service provision. For example, many everyday tasks undertaken by government or private companies use ICT to improve efficiency, enhance service provision, and improve community access to and uptake of information, while still allowing for direct interpersonal communication as needed. ${ }^{23}$ While large e-government programs have generally been successful in high-income countries, ${ }^{24}$ they have been less so in LMIC, with a complete failure rate of over $30 \%$, or more alarmingly, only a seventh of initiatives deemed successful. ${ }^{25}$ Similar lack of success in an earlier study was explained by technical factors, such as late delivery of technical systems, software problems and lack of adequate training, along with a lack of political support, resistance to change, insufficient consultation with stakeholders, poor adaptation to the local context and mistrust. ${ }^{26}$ We should note, these problems must be considered when reforming public services in general; they are not exclusive to projects involving new technology.

\section{Where to From Here?}

Current technological advances are helping the formal education sector to develop new delivery modes that can meet, at low cost, the demand for continuing education and retraining of the global workforce. The question for governments, universities, colleges, and private businesses is not whether but how to employ technology to engage distant and mobile learners. Likewise, given the continuous need for capacity building of local health managers and the current costs and logistic barriers imposed by traditional face-to-face instruction, ${ }^{14}$ governments have no option but to exploit technological and pedagogical advances in the formal education sector. Web-based approaches can benefit staff in remote areas. ${ }^{14}$ In developing countries, already improving their ICT systems, the limitations of future development may relate more to work and political constraints, and the contextualisation, tailoring of and support for the content. Adequate and sustained investments by donors and governments in higher education institutions are required to take blended learning initiatives to scale. These investments should address not only the technical aspects of delivery, but also the capacity gaps for teaching staff. Robust instruction designs are crucial for the success of any online and blended learning courses, but current capacity in developing countries is limited in this regard. 
Blended approaches to capacity building can provide adequate opportunities for interaction between groups of health managers and between them and their trainers or mentors at a reasonable cost. Such approaches will require strong support from government, donor and educational institutions; their buy-in is also crucial to achieve economies of scale and to facilitate learning and familiarity with such new platforms. Currently, the full potential of blended learning for both the education sector and as an approach to capacitate local health managers is yet to be realised. Different models should be piloted and evaluated in different settings to provide more information on the best ways to realise this potential.

\section{Ethical issues}

Not applicable.

\section{Competing interests}

The authors declare that they have no competing interests. Any opinions stated are those of the authors and not of their parent institutions.

\section{Authors' contributions}

EJS conceptualised the research. HM undertook the literature search, collected the data, and synthesized the results. EJS and HM drafted the manuscript. SF and $\mathrm{DH}$ contributed to themes analysis and reviewed the draft manuscript. All authors contributed significantly to revisions and approved the final manuscript.

Authors' affiliations

${ }^{1}$ School of Public Health, The University of Queensland, Brisbane, QLD, Australia. 'United Nations Children's Fund (UNICEF), New York City, NY, USA.

\section{References}

1. Langenbrunner J, Somanathan A. Financing Health Care in East Asia and the Pacific: Best Practices and Remaining Challenges. Washington, DC: World Bank; 2011.

2. Rockers PC, Bärnighausen T. Interventions for hiring, retaining and training district health systems managers in low-and middle-income countries. Cochrane Database Syst Rev. 2013; 3:CD009035. doi:10.1002/14651858.CD009035

3. Hodge A, Firth S, Marthias T, Jimenez-Soto E. Location matters: trends in inequalities in child mortality in Indonesia. Evidence from repeated cross-sectional surveys. PLoS One. 2014;9(7):e103597. doi:10.1371/journal.pone.0103597

4. Bauze AE, Tran LN, Nguyen K-H, et al. Equity and geography: the case of child mortality in Papua New Guinea. PLoS One. 2012;7(5):e37861. doi:10.1371/journal.pone.0037861

5. Dettrick Z, Jimenez-Soto E, Hodge A. Socioeconomic and geographical disparities in under-five and neonatal mortality in Uttar Pradesh, India. Matern Child Health J. 2014;18(4):960969. doi:10.1007/s10995-013-1324-8

6. The World Bank. Local Solutions for Local Problems. http://www. worldbank.org/en/news/feature/2013/07/03/Local-Solutions-forLocal-Problems. Published June 25, 2013.

7. Ranson MK, Chopra M, Atkins S, Dal Poz MR, Bennett S. Priorities for research into human resources for health in low- and middle-income countries. Bull World Health Organ. 2010;88(6):435-443. doi:10.2471/BLT.09.066290

8. Joynes C. Distance learning for health: a global review of accredited post-qualification training programmes for health workers in low and middle income countries. http://www.lidc.org. uk/_assets/DL4H_Report_Full_reduced.pdf. Published 2011.

9. Kim K-J, Frick TW. Changes in student motivation during online learning. Journal of Educational Computing Research. 2011;44(1):1-23.

10. Kundi M, NawazA. From e-Learning 1.0 to e-Learning 2.0: threats \& opportunities for higher education institutions in the developing countries. European Journal of Sustainable Development. 2014;3(1):145-160. doi:10.14207/ejsd.2014.v3n1p145

11. Dolan VL. Massive online obsessive compulsion: what are they saying out there about the latest phenomenon in higher education? The International Review of Research in Open and Distance Learning. 2014;15(2). http://www.irrodl.org/index.php/ irrodl/article/view/1553/2893.

12. US Department of Education. Evaluation of Evidence-Based Practices in Online Learning. https://www2.ed.gov/rschstat/ eval/tech/evidence-based-practices/finalreport.pdf. Accessed 22 June, 2015. Published 2010.

13. So H-J, Brush TA. Student perceptions of collaborative learning, social presence and satisfaction in a blended learning environment: relationships and critical factors. Comput Educ. 2008;51(1):318-336. doi:10.1016/j.compedu.2007.05.009

14. Maloney S, Haas R, Keating JL, et al. Breakeven, cost benefit, cost effectiveness, and willingness to pay for web-based versus face-to-face education delivery for health professionals. J Med Internet Res. 2012;14(2):e47. doi:10.2196/jmir.2040

15. Sharma P. Blended learning. ELT Journal. 2010;64(4):456-459. doi:10.1093/elt/ccq043

16. Reynold S, Fell P. The effect of e-learning on student placement in the community. Prim Health Care. 2011;21(5):28-32. doi:10.7748/phc2011.06.21.5.28.c8549

17. Macharia J. Internet access is no longer a luxury. http://www. un.org/africarenewal/magazine/april-2014/internet-access-nolonger-luxury. Published April 2014.

18. International Telecommunications Union (ITU). ICT Facts \& Figures. http://www.itu.int/en/ITU-D/Statistics/Pages/facts/default. aspx. Accessed 23 June, 2015. Published 2015.

19. Bhuasiri W, Xaymoungkhoun $\mathrm{O}$, Zo H, Rho JJ, Ciganek AP. Critical success factors for e-learning in developing countries: A comparative analysis between ICT experts and faculty. Comput Educ. 2012;58(2):843-855.

20. Liu I-F, Chen MC, Sun YS, Wible D, Kuo C-H. Extending the TAM model to explore the factors that affect Intention to Use an Online Learning Community. Comput Educ. 2010;54(2):600-610.

21. DiPietro M, Ferdig RE, Black EW, Preston M. Best practices in teaching K-12 online: Lessons learned from Michigan Virtual school teachers. Journal of Interactive Online Learning. 2008;7(1):10-35

22. Delfino M, Persico D. Online or face-to-face? Experimenting with different techniques in teacher training. Journal of Computer Assisted Learning. 2007;23(5):351-365.

23. United Nations. E-Government Survey 2014: E-Government for the Future We Want. http://unpan3.un.org/egovkb/Portals/egovkb/ Documents/un/2014-Survey/E-Gov_Complete_Survey-2014.pdf. Published 2014.

24. Basu S. E-government and developing countries: an overview. International Review of Law, Computers \& Technology. 2004;18(1):109-132.

25. Alghamdi IA, Goodwin R, Rampersad G. E-government readiness assessment for government organizations in developing countries. Computer and Information Science. 2011;4(3):3-17. doi:10.5539/cis.v4n3p3

26. Heeks R. eGovernment for Development: Success and Failure in eGovernment Projects. http://www.egov4dev.org/success/ sfrates.shtml. Published 2008. 